\title{
Nora's Story
}

\author{
Nora Gibbons
}

\begin{abstract}
In this column, Nora Gibbons, 16 years old, describes the home births of four of her siblings. Nora's story captures the wonder and simplicity of home birth and demonstrates the impact the experience of being present at home birth can have on children. Nora's joy and confidence in birth because of her experiences will influence her own birth choices.
\end{abstract}

The Journal of Perinatal Education, 24(1), 6-7, http://dx.doi.org/10.1891/1058-1243.24.1.6

Keywords: home birth, normal birth, confident birth, children at birth

On a Saturday night when I was 11, I put on pajamas and my purple bathrobe, watched a movie with my sisters, and went to sleep. A few hours later, when my father quietly woke me, I put on my purple bathrobe again and watched as my mother gave birth. That night was extraordinary and magical and not strange or unexpected to me in the slightest. This was the third of my mother's home births I had witnessed. Most of my friends had to wait hours or days or even more to be introduced to their new siblings, while I have had the privilege of meeting and falling in love with three of mine from their very first moments.

My mother has had six children, and after giving birth to me and my sister, Molly, in a birthing center, she chose home births with a midwife for my four youngest siblings. While at Molly's birth I was still too young to remember anything, the births of Maggie, Cate, Claire, and Robbie have all had profound and lasting effects on me.

When Maggie was born, I was 4 years old. Molly and I watched Dora the Explorer upstairs with our aunt while my mother gave birth to Maggie in her bedroom. Within moments of Maggie's birth, Molly and I eagerly raced downstairs. We had chosen matching pink pajamas with pigs on them for us and the baby to wear and we helped as my grandmother and the midwife dressed her. Although I was not in the room while my mother was in labor with Maggie, this experience still set the stage for my own perceptions of birth. It was a celebration. Our house grew full with friends and family, eating, drinking, and honoring my mother's hard work and Maggie's entrance into the world. Molly and I pranced around the festivities, proud to have acquired this wonderful new sister into our ranks and delighted to be a part of the experience.

Although I got to meet Maggie soon after her birth, much sooner than I could have had she been born in a hospital, I still wanted to be more involved during my next sibling's birth. When my parents asked each of us what we wanted to do on the day the baby would be born, we each were sure of our decisions. Molly wanted to see the baby once she was clean, Maggie wanted to see the baby once she was dressed, and I wanted to see the baby from the very beginning, as she was born. I could not wait. Every day in school, I'd stare at the door, constantly ready to race home should the call come that my mother was in labor. When the time finally came, I didn't have to jump out of my desk at school but out of my bed in the middle of the night. I sat on my grandmother's lap in a blue chair in my parents' bedroom as I 
watched my mother give birth to Cate. The next day in school, I wrote and illustrated a book about it. "Cate's head looked like a soccer ball. There was a lot of blood," I wrote and shared with my first-grade class. I knew that none of my classmates really knew about home births, let alone had they seen one. Many seemed surprised, but to me, it had been the most natural-seeming experience in the world. What would have been so normal about sitting in a hospital waiting room?

By the time Claire was born, I was barely even surprised at being awoken in the night. Again I waited in my living room, sipping Irish tea on the couch. I then sat on the blue chair in the bedroom, watching once again a most amazing feat as my mother pushed Claire into the world. Before long the rest of my sisters had joined everyone, and we all held and stroked and gazed at tiny, perfect Claire. I went to school late and announced Claire's birth with bubble gum and chocolate cigars that my thirdgrade class all clamored for, then waited restlessly for the end of the day when I could return home and go back to admiring that gorgeous baby.

Robbie's birth was the most recent and the one, which I can recall most vividly. That night, I made dinner with my father. We made risotto and chicken cutlets, and I felt proud and accomplished that I'd finally been promoted from stirrer to chicken cooker. After that seemingly mundane day, I went to sleep only to be woken up a few hours later when my father tapped on the bars of my bunk bed. I knew immediately and almost intrinsically, even while half asleep, that it was time for the baby to come, and I sprang out of bed. One of my aunts arrived with a pizza and I ate and waited with my sisters, grandmother, and aunt. My mother paced and shook her arms, as I'd seen her do with the last two births. My father went around covering the clocks in the house with construction paper, so that the passing time would not make her anxious. Miriam, the midwife, was, as usual, a calming and soothing presence. The whole house buzzed with anticipation but not anxiousness. The baby would arrive when the baby was ready. I wrote in my journal at the time, "The excitement in the air buzzed quietly, like music played nearly on mute." My mother soon gave birth to Robbie, and I watched as she did this beautiful and natural job with confidence and strength. I saw his hand, which was over his head covering his ears, slowly emerge, quickly followed by his slippery slim shoulders and the rest of his body. We now joke that he arrived already preparing himself for life with five loud sisters. Robbie was not prodded, poked, or blood tested, or whisked away from us for any unnecessary tests. When

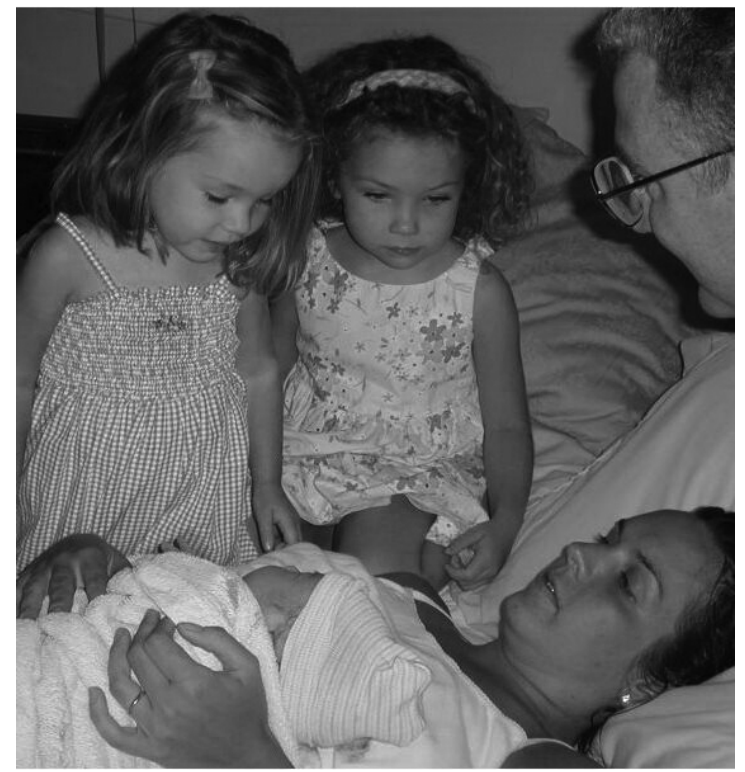

Big sisters Nora (center, in headband) and Molly greet baby Maggie minutes after birth.

he was measured, cleaned, and clothed, he was never far from my mother. We all held him and kissed him and stared in awe at his brand new little face. As the celebration started in full swing, I didn't just feel wonder at Robbie's birth but also appreciation for my mother and all she had taught me through giving me the opportunity to be so involved in this process.

Watching the births of each of my siblings, I learned of the miraculous beauty and power that comes from acknowledging and trusting in your own strength and ability. Until recently, I had never met anyone my own age who had been present at a home birth. When I discovered one of my friends had watched her aunt's home births, she told me that it surprised her that women would choose to experience one of the best days of their lives in an unfamiliar hospital with doctors and nurses who they did not know, when instead they could choose be in their own comfortable homes, surrounded by friends and family. My mother chose to have some of the most important experiences of her life in our home with faith in herself to give birth naturally and gracefully. I am so incredibly thankful to my mother for showing me this possibility and inspiring me, so that when the time comes for me to give birth, I too can have the confidence to choose this path.

NORA GIBBONS, 16 years old, is a junior in high school. She lives with her parents and five siblings in Missoula, Montana. She loves writing, reading, travel, and good food. She is an advocate for home birth. 